Review

\title{
Dysfunction of transient receptor potential ion channels as an important pathophysiological mechanism in asthma
}

\author{
Oxana Y. Kytikova, Tatyana P. Novgorodtseva, Yulia K. Denisenko, Marina V. Antonyuk, Tatyana A. Gvozdenko \\ Vladivostok Branch of Far Eastern Scientific Center of Physiology and Pathology of Respiration - Institute of Medical Climatology and \\ Rehabilitative Treatment, Vladivostok, Russia
}

Received 10 July 2019, Revised 6 November 2019, Accepted 18 February 2020

(c) 2019, Kytikova O.Y., Novgorodtseva T.P., Denisenko Y.K., Antonyuk M.V., Gvozdenko T.A.
(c) 2019, Russian Open Medical Journal

Abstract: Asthma is a chronic heterogeneous disease characterized by chronic inflammation and bronchial hyperreactivity. Neurogenic inflammation is one of the important causes of hyperreactivity. Dysfunction of transient receptor potential (TRP) ion channels underlies the development of neurogenic inflammation, bronchial hyperreactivity and respiratory symptoms of asthma such as bronchospasm and cough. TRP channels are expressed in the respiratory tract. Their activation is mediated by endogenous and exogenous factors involved in the pathogenesis of asthma. The study of functioning and regulation of TRP channels is relevant, as they could be important therapeutic targets for asthma. The aim of the review is to summarize modern ideas about the mechanisms of functioning and regulation of members of the TRP channel superfamily, the role of which in lung pathology and physiology are the best studied.

Keywords: asthma, transient receptor potential ion channels.

Cite as Kytikova OY, Novgorodtseva TP, Denisenko YK, Antonyuk MV, Gvozdenko TA. Dysfunction of transient receptor potential ion channels as an important pathophysiological mechanism in asthma. Russian Open Medical Journal 2020; 9: e0102.

Correspondence to Oxana Yu. Kytikova. Addres: Russkaya str., 73g, 690105, Vladivostok, Russia. Phone: +7 4232788201. E-mail: kytikova@yandex.ru.

\section{Introduction}

Asthma is a heavy socio-economic burden for the healthcare system and efforts to find effective therapeutic strategies for this pathology remains relevant for many decades [1, 2]. It indicates the multifactorial nature of the disease and the complexity of its pathophysiological mechanisms.

Asthma is a heterogeneous progressive disease with high variability caused by genetic predisposition, the influence of climatic and anthropogenic environmental factors, as well as an ability of the bronchi to respond immediately to several trigger factors through the development of bronchospasm [3].

Bronchial hyperreactivity and chronic inflammation are important pathogenetic mechanisms of asthma [3]. One of the reasons for the development of hyperreactivity is an imbalance in the relationships between immune and nerve cells, denoted by the term "neurogenic inflammation" [4]. The adrenergic, cholinergic and nonadrenergic non-cholinergic nervous systems innervate the airways [5]. Non-myelinated, nociceptive C-fibers of the lungs participate in sensory innervation of the mucous membrane of the respiratory tract and are involved in the pathogenesis of asthma [6]. The stimulation of C-fibers is accompanied by the release of neuropeptides (substance P (SP), vasoactive intestinal peptide (VIP), calcitonin gene related peptide (CGRP), tachykinins, neuropeptide $Y$ (NPY), bombesins, granins) [7]. An imbalance between stimulating and inhibiting neuropeptides has been noted in prolonged airway inflammation [8]. Neurons interact with immune cells through neuropeptides, modulating the development of Th2-associated immune response and chronic neurogenic inflammation. On the other hand, the immune system activates sensory neurons, mediating the development of hyperreactivity and subsequent bronchospasm in asthma.

In addition to bronchospasm, repeated episodes of wheezing, shortness of breath, chest tightness and coughing have been observed in asthma [3]. The cough reflex has a complex neurogenic pathway and is regulated by sensitive vagal afferent nerves that innervate the airways [9]. The high sensitivity of the bronchi to the action of climatic factors (low temperature and high humidity) is also associated with impaired regulation of sensitive afferent nerves of the respiratory tract and the development of chronic neurogenic inflammation [10].

Thus, nociceptive neurons are involved in airway inflammation by initiating local neurogenic inflammation and activating bronchoconstriction.

It has been established that the sensitivity of airway nociceptors is associated with the activity of a new class of membrane proteins - members of the transient receptor potential (TRP) ion channel superfamily [9]. The data presented in the literature convincingly indicate the role of TRP channels in the initiation of neurogenic inflammation and the formation of some reactions of the respiratory tract in asthma, which are mediated by the influence of endogenous and exogenous factors [11-13]. Obviously, further research on functioning and regulation of TRP channels is relevant, as they could be important therapeutic targets for the treatment of asthma [14]. 
The scientific publications on a given topic were searched for in the PubMed database over the past 10 years. The review included only those sources of information that highlighted the structure and functioning of TRP ion channels in asthma, exogenous and endogenous factors modulating their activity. The following keywords were used: "Transient Receptor Potential channels asthma". The found titles of articles were looked through and, if they corresponded to the topics of the literary review, the abstracts of the articles were analyzed. If the abstract met the inclusion criteria, a search and analysis of the full-text version of the article were performed.

\section{Characterization of TRP ion channels localized in the bronchopulmonary system}

TRP channels are an extensive group (superfamily) of integral membrane proteins that have identical structure, fulfill the functions of ion channels and react to various chemical, thermal and mechanical stimuli [15].

The mammalian TRP superfamily consists of 28 channels grouped into 6 subfamilies. Several subunits are distinguished in each subfamily: canonical (TRPC 1-7), vanilloid (TRPV 1-6), polycystin (TRPP 1-3), mucolipin (TRPML 1-3), ankyrin (TRPA 1) and melastatin (TRPM 1-8) [12, 13]. In addition, TRPN receptors (no mechanopotential (NOMP)), which are similar to canonical ones but not responding to mechanical stimuli, have been found in invertebrates and fish.

TRP channels are expressed primarily by neurons $[16,17]$. At the same time, some channels have also been found on other cells, in particular on cells of the respiratory tract (bronchial epithelium and endothelium, smooth muscle cells, non-myelinated nociceptive $C$-fibers of the lungs) $[17,18]$.

TRPA1, TRPV, TRPC, TRPM expressed in the respiratory tract are the most studied. The sensitivity of nociceptors involved in neurogenic inflammation in the bronchopulmonary system is largely associated with TRPA1 and TRPV1 [14].

\section{TRPA1}

The TRPA1 channel has for a long time been considered as a protein mainly expressed by nociceptors and perceiving external chemical, physical and mechanical stimuli initiating acute pain. However, in recent years, its presence has been established in Tcells, B-cells, mast cells, as well as in nociceptive C-fibers of the lungs involved in pathogenetic mechanisms of the development and progression of asthma [19]. TRPA1 is involved in the initiation of chronic airway inflammation primarily as a protective mechanism of the lungs along with TRPV1. However, excessive stimulation of the receptor by reactive oxygen species and lipid peroxidation products in pathology or endogenous irritants of the respiratory tract (ozone, acrolein, etc.) may be associated with the development of chronic inflammation. It is believed that TRPA1 receptor activation is an important mechanism of neurogenic airway inflammation and TRPA1 antagonists could play a significant role in the treatment of asthma [14].

\section{TRPV}

Despite the fact that TRPV channels are predominantly localized on nociceptive neurons, a significant number of these receptors has been noted in sensory nerve fibers of the respiratory tract, on bronchial epithelial cells, mast cells, macrophages and smooth muscle cells [20]. These channels are involved in the synthesis of pro-inflammatory mediators, mucus hypersecretion and the contraction of bronchial smooth muscles [21].

The release of pro-inflammatory cytokines initiating chronic inflammation of the respiratory tract is associated with TRPV1 activation [22]. Despite the low level of TRPV1 expression in the lung tissue in healthy subjects [19], it is increased in patients with asthma [23]. It has been revealed that TRPV1 expression is a statistically significant increased in the bronchi in asthma patients who did not respond to standard therapy compared to patients who responded to the treatment. It suggests a significant role of these channels in severe difficult-to-control asthma [24].

TRPV4 is currently one of the most actively studied TRPV channels $[25,26]$. TRPV4 is widely expressed in the heart, kidneys, skin, sweat glands, nociceptive neurons, as well as in the epithelial cells of the bronchi and sensory nerve fibers of the respiratory tract $[17,27]$. The role of this channel in the pathogenesis of asthma has been poorly studied [28].

\section{TRPC}

TRPC channels are expressed in various tissues, but TRPC4 and TRPC5 are predominantly localized in the nervous system. TRPC1 channel activation is involved in the development of inflammation and airway remodeling $[29,30]$. In addition, bronchoconstriction and cough, which are characteristic of an asthmatic reaction, is mechanical stress to the airway that induces TRPC1 activation and promotes airway remodeling [31].

TRPC6 is expressed in lung tissue and activated under hypoxia [32], but its role in the pathophysiology of asthma needs to be studied further.

\section{TRPM}

Currently, among the TRPM channels, the role of TRPM8 in inflammation and airway remodeling in asthma is more actively studied [14]. Recent studies have shown that TRPM8 is expressed not only by sensitive neurons but also in various organs and tissues, including epithelial and smooth muscle cells of the respiratory tract [33]. The activation of TRPM8 in lung epithelial cells leads to an increase in the expression of cytokines, chemokines and mucus hypersecretion [33]. At the same time, the pro-inflammatory mediators, such as bradykinin and prostaglandin E2 (PGE2), as well as the acidity change observed in inflammation inhibit the activity of the channel.

Thus, TRPA1, TRPV1, TRPV4, TRPC1, TRPC6 and TRPM8 channels are expressed in the bronchopulmonary system and are involved in the pathogenesis of asthma. However, the additional and comprehensive study of mechanisms of modulation of their activity is required to develop new therapeutic strategies for this disease.

Exogenous and endogenous factors modulating the activity of TRP ion channels in the respiratory tract

TRP channels expressed in the airways may be activated by both exogenous and endogenous factors. A number of these triggers play an important role in the development and progression of asthma [34, 35].

The main differences of the TRP superfamily from other ion channel families are predominant localization in neuronal cells and 
reactions to known exogenous stimuli, such as temperature, chemicals, light and sound [15, 36].

TRP channels expressed by non-neuronal cells are predominantly activated by endogenous factors [17, 18]. The modulation of TRP channels may be due to the exposure to bradykinin, histamine, phosphatidylinositol-4,5-bisphosphate (PIP2), neurokinin and PGE2 [37]. TRP activity also depends on the impact of bioactive lipids, such as phosphatidylcholine, phosphatidylethanolamine, cholesterol, phosphatidylinositol-4,5bisphosphate, polyunsaturated fatty acids (PUFAs) and endogenous cannabinoids, as well as changes in $\mathrm{pH}$, membrane potential and intracellular calcium ion concentration $\left(\mathrm{Ca}^{2+}\right)[38$, 39].

The regulation of these channels by various stimuli makes them an extremely attractive therapeutic target.

\section{Temperature}

TRP channel subfamilies are characterized by the ability to respond to thermal stimulation [36]. The temperature range for activation of TRPA 1 and TRPM 8 is $8-28^{\circ} \mathrm{C}$, TRPV3 and TRPV4 react to $27-35^{\circ} \mathrm{C}$, TRPV1 is activated by even higher temperature, and the temperature for TRPV2 triggering is above $52^{\circ} \mathrm{C}[15]$.

TRPA 1 and TRPM 8 are activated by cold air $[33,37]$ that is an important trigger factor for the development of severe asthma in patients with cold airway hyperresponsiveness [10, 40]. Some studies have shown that cold air induces an inflammatory reaction of the respiratory tract and the development of bronchial remodeling by altering the expression of TRPA1 and TRPM8 [38].

The combination of cold air and high humidity is also accompanied by the development of a bronchospastic reaction and asthma-like symptoms (coughing, wheezing, shortness of breath) in patients with asthma, increasing the frequency of exacerbations and reducing disease control [41, 42]. The development of bronchospasm and asthma-like symptoms in response to exposure to hyper- and hypoosmolar exogenous stimuli are mediated by TRPV channels (TRPV1, TRPV4 and probably TRPV2). The development of new methods of the treatment of asthma exacerbations caused by the influence of cold air should be based on the regulation of activity of TRPA1, TRPM8 and TRPV channels.

Currently, these channels are considered as the main sensors perceiving physicochemical stimuli of the external environment $[33,37]$.

\section{Bioactive lipids}

Among the listed endogenous stimuli, endogenous cannabinoids play the most important role in channel activation. Endogenous cannabinoids, which are derivatives of arachidonic acid (AA) (namely anandamide and 2-arachidonoylglycerol (2-AG)), and cannabinoid receptors of the first and second types (CB1 and CB2) are the most studied [43]. Endocannabinoids, cannabinoid receptors for the psychoactive ingredients of marijuana ( $\Delta 9$ tetrahydrocannabinol) and the enzymatic systems, which are involved in the synthesis, metabolism and degradation of these compounds, form the endocannabinoid system [44]. In addition to $\mathrm{CB}$ receptors, anandamide and $2-\mathrm{AG}$ is also able to bind and activate TRPV (TRPV1, TRPV2, TRPV3, TRPV4), TRPA1 and TRPM8 [45]. Anandamide was the first detected endogenous TRPV1 and TRPM8 antagonist. 2-AG also acts as an agonist of TRPV1 channel
[46]. Besides that, $\triangle 9$-tetrahydrocannabinol affects TRPV2, TRPV3, TRPV4, TRPA1 and TRPM8.

The levels of circulating endocannabinoids are significantly increased in asthma [47, 48], and their ability to modulate the activity of TRPV and TRPM8 channels deserves close attention.

Lysophospholipids, PUFAs and PIP2 are factors modulating the activity of TRP channels, in particular TRPM8. Lysophospholipids increase the temperature threshold of the channel activation and PUFAs (arachidonic, eicosopentaenoic, docosahexaenoic acids), conversely, inhibits the channel activation by cold and menthol. TRPM8 is activated at $32-37^{\circ} \mathrm{C}$ under the condition of a high concentration of phospholipid PIP2.

Numerous studies have shown that TRPV ion channels (TRPV1, TRPV4) are sensitive to the level of membrane cholesterol, which is one of the main lipid components of the plasma membrane of the most eucaryotic cells [49-51]. Cholesterol is necessary to maintain membrane fluidity, membrane thickness and the compartmentalization of lipid domains. However, an increase in the level of membrane cholesterol underlies the development of cell dysfunction and pathology [52, 53]. The physicochemical properties of lipid rafts are regulated by the presence of cholesterol [54], the maintenance of calcium ion balance [55] and the presence of exogenous fatty acids [56]. Richard G.C. et al. have emphasized the close relationship between fatty acid synthesis and cholesterol synthesis [57]. There is a constant exchange between the membrane proteins of the lipid raft and the surrounding lipid bilayer. Therefore, the violation of cholesterol metabolism leads to the disorder of the functioning of the lipid raft and, accordingly, the signaling pathways of the cell [58]. There are two mechanisms of lipid-protein interactions: specific interactions or changes in the physicochemical properties of the membrane affecting the dynamics of ion channels [59].

It has been established that TRPV channels are regulated by cholesterol-protein interactions [60]. Several recent studies have identified a number of motifs (two amino acid sequences) responsible for cholesterol binding that has made it possible to understand the features of the interaction of cholesterol and ion channels $[50,61]$. On the one hand, cholesterol can interact with the channel protein and regulate its function as a ligand and, on the other hand, it regulates the channel functions by changing the stiffness of the lipid bilayer that in turn affects the function of the protein [62].

It is obvious that endocannabinoids, cholesterol, lysophospholipids, PUFAs and PIP2 are able to modulate the activity of TRPV channels, it emphasizes the need for further research.

Acidity, membrane potential and intracellular calcium ion concentration

TRP activity also depends on $\mathrm{pH}$, membrane potential and intracellular $\mathrm{Ca}^{2+}$ concentration.

The impact of trigger factors leads to the opening of the channel due to a change in the membrane potential required for the activation. TRP channels are permeable to $\mathrm{Na}^{+}, \mathrm{K}^{+}, \mathrm{Mg}^{2+}$ and $\mathrm{Ca}^{2+}$ ions [63]. At the same time, different channel families have different selective permeability and can be permeable only to $\mathrm{Ca}^{2+}$ ions, or only to monovalent cations, or not have valence specificity. It is noteworthy that after activation the channel can be modulated by completely different mechanisms, which can not be 
predicted on the basis of its belonging to a particular TRP subfamily. $\mathrm{Na}^{+}$and $\mathrm{K}^{+}$are involved in the regulation of bronchial patency and functions of cells participated in the development of inflammatory changes in the bronchopulmonary system. $\mathrm{Ca}^{2+}$ is a messenger of signaling cascades responsible for the synthesis and secretion of inflammatory mediators, mucin hypersecretion and bronchial smooth muscle contraction [24]. In addition, TRP activation is accompanied by an influx of extracellular $\mathrm{Ca}^{2+}$ ions and the release of neuropeptides in peripheral tissues and the spinal cord that causes the development of neurogenic inflammation [64].

TRPV1, TRPV4, TRPM8, TRPC1, TRPA1 channels play an important role in intracellular $\mathrm{Ca}^{2+}$ dysregulation $[24,65]$. The stimulation of airway epithelial cells by lipopolysaccharides (LPS), which are part of the wall of gram-negative bacteria and play a crucial role in the immune response in asthma, leads to an increase in $\mathrm{Ca}^{2+}$ concentration mediated by TRPV4 channels. The observed increase in nitric oxide production testifies to the protective role of TRPV4 [66]. $\mathrm{Ca}^{2+}$ influx caused by TRPC1 activation regulates and stimulates cell proliferation, differentiation, secretion and migration, as well as modulates the expression of chemokines and cytokines, such as interleukin-13 (IL13), matrix metalloproteinases-9 $[29,30]$.

Thus, the activation of TRP channels expressed in the airways can be mediated by the influence of both exogenous and endogenous factors. Nociceptors involved in neurogenic inflammation in asthma are associated with TRPA1 and TRPV1. TRPV1 channel is activated by the influence of hyper- and hypoosmolar exogenous stimuli, endogenous cannabinoids and other bioactive lipids. TRPA1 channel is activated by cold. In addition, changes in the activity of both TRPA1 and TRPV1 depend on $\mathrm{pH}$ acidity, membrane potential and intracellular concentration of $\mathrm{Ca}^{2+}$ ions. The above data highlight the undoubted relevance of the further study of disorders in TRP channel expression in asthma for practical pulmonology.

\section{The disorder of TRP ion channel expression in asthma}

TRP channels are involved in inflammatory and structural changes in the respiratory tract resulting in the development of bronchial hyperreactivity and bronchospasm [67].

Non-myelinated nociceptive C-fibers expressing TRP channels are involved in sensory innervation of the mucous membrane of the respiratory tract. Trigger factors stimulate the peripheral parts of the nociceptor and activate the channels (mainly TRPV1 and TRPA1) resulting in the release of neurotransmitters and the development of neurogenic inflammation in the airways.

Thus, TRPA1 expression by C-fibers of the respiratory tract caused endogenous factors is accompanied by an influx of extracellular $\mathrm{Ca}^{2+}$ ions and the release of pro-inflammatory neuropeptides (SP, CGRP, neurokinin A) and the development of bronchospasm [64]. The role of TRPA1 channels in the activation of sensory nerves of the lungs and the formation of bronchoconstriction has been established in both allergic [68] and non-allergic asthma [69]. TRPV1 channel agonists also cause bronchoconstriction in humans and animals through the development of neurogenic inflammation [22]. Neuropeptide SP is considered as an important mediator of neurogenic inflammation causing edema, mucus hypersecretion and initiating bronchospasm [8]. This pleiotropic peptide stimulates the production of granulocyte-macrophage colony-stimulating factor
(GM-CSF), which regulates the proliferation and differentiation of progenitor cells of monocytes, neutrophils, macrophages and dendritic cells. SP also has the ability to stimulate the release of pro-inflammatory cytokines (IL-1, IL-6, IL-8, tumor necrosis factor$\alpha(T N F-\alpha))$ by human bronchial epithelial cells and cause bronchospasm. CGRP receptors play an important role in the release of certain pro-inflammatory cytokines, chemokines and inflammatory mediators. They, in turn, mediate mucus hypersecretion and the narrowing of airways [70].

Bronchospasm and asthma-like symptoms that develop in response to exposure to cold air and high humidity are due to the participation of TRPV channels (TRPV1, TRPV4 and probably TRPV2) in osmoreception [10, 71, 72]. The violation of osmolarity of the intrabronchial environment is accompanied by the formation of lipid peroxidation products, the activation of mast cells, the secretion of neurotransmitters and cytokines [73], which mediate the development of bronchial obstruction, the impairment of the mucociliary system and the activation of the cough reflex. Changes in the structure and function of the mucociliary system are involved in the formation of airway hyperresponsiveness.

Particular attention is paid to TRP-mediated induction of cough as the result of the inhalation of irritating environmental reagents and the development of bronchopulmonary pathology [39]. On the one hand, the activation of these channels in the nerve endings of the respiratory tract leads to the stimulation of protective reflexes (cough, elevated mucus production, increased mucociliary clearance). On the other hand, it can be a pathogenetic basis for the formation of the disease under certain conditions [39,67]. The pathogenesis of the cough reflex involves the TRPV1 channel [39]. The release of pro-inflammatory mediators, which activate or sensitize TRPV1 channels (prostaglandin, bradykinin, lipoxygenase metabolites), is accompanied by the appearance of cough [74]. It is known that the decrease in $\mathrm{pH}$ observed in the affected airways also contributes to the activation of TRPV1 channels. In this regard, these channels are considered as a potential pharmacological target for antitussive therapy [14]. Currently, the clinical trials of a number of compounds modulating TRP channels (TRPV1, TRPV3, TRPV4, TRPA1, TRPM8) have carried out [1].

\section{Conclusion}

Currently, it is known that the pathogenesis of asthma involves not only the mechanisms of chronic inflammation mediated by allergic reactions, but also the mechanisms of neurogenic inflammation. Nociceptive C-fibers of the lungs expressing TRP channels are involved in the innervation of the mucous membrane of the respiratory tract. The exogenous and endogenous trigger factors stimulate peripheral parts of the nociceptor and activate TRP channels thereby initiating the release of neurotransmitters and the development of neurogenic inflammation. In addition, the dysfunction of TRP ion channels is the pathogenetic basis of respiratory symptoms accompanying asthma, such as bronchospasm and cough.

Therefore, the relevance of the further study of the functioning and regulation of TRP channels is undeniable, since they can be new and effective therapeutic targets in asthma. The modulators of TRP receptor activity can have an anti-inflammatory effect by blocking the participation of some neurons in chronic inflammation in asthma. 


\section{Conflict of interest}

We declare that we have no conflict of interest.

\section{References}

1. Moran MM. TRP channels as potential drug targets. Annu Rev Pharmacol Toxicol 2018; 309-330. https://doi.org/10.1146/annurev-pharmtox-010617-052832.

2. Kytikova O, Gvozdenko T, Antonyuk M. Modern aspects of prevalence of chronic bronchopulmonary diseases. Bull Physiol Pathol Respir 2017; (64): 94-100.

Russian. https://doi.org/10.12737/article 5936346fdfc1f3.32482903.

3. Global Initiative for Asthma. Global strategy for asthma management and prevention. 2019. https://ginasthma.org/gina-reports/.

4. Sacchetti M, Segatto M, Bruscolini A, Abicca I, Cavaliere C, Lambiase A. Changes of NGF pathway in allergic rhinoconjunctivitis: a conjunctival allergen challenge study. Allergy 2018; 74(3): 605-607. https://doi.org/10.1111/all.13641.

5. Mazzone SB, Undem BJ. Vagal afferent innervation of the airways in health and disease. Physiol Rev 2016; 96(3): 975-1024. https://doi.org/10.1152/physrev.00039.2015.

6. Talbot $S$, Abdulnour RE, Burkett PR, Lee $S$, Cronin SJ, Pascal MA, et al. Silencing nociceptor neurons reduces allergic airway inflammation. Neuron 2015; 87(2): 341-354. https://doi.org/10.1016/j.neuron.2015.06.007.

7. Atanasova KR, Reznikov LR. Neuropeptides in asthma, chronic obstructive pulmonary disease and cystic fibrosis. Respir Res 2018; 19(1): 149. https://doi.org/10.1186/s12931-018-0846-4

8. Sun J, Bhatia M. Substance $P$ at the neuro-immune crosstalk in the modulation of inflammation, asthma and antimicrobial host defense. Inflamm Allergy Drug Targets 2014; 13(2): 112-120. https://doi.org/10.2174/1871528113666140323202419.

9. Lee LY, Yu J. Sensory nerves in lung and airways. Compr Physiol 2014; 4(1): 287-324. https://doi.org/10.1002/cphy.c130020.

10. Pirogov AB, Prikhod'ko AG, Gassan DA, Mal'tseva TA, Kolosov VP, Perel'man YuM. Efficacy of antiinflammatory therapy in patients with severe asthma and cold air-provoked bronchial hyperresponsiveness. Pulmonology 2018; 28(5): 576-583. https://doi.org/10.18093/08690189-2018-28-5-576-583.

11. Belvisi MG, Birrell MA. The emerging role of transient receptor potential channels in chronic lung disease. Eur Respir J 2017; 50: 1601357. https://doi.org/10.1183/13993003.01357-2016.

12. Storch $U$, Forst AL, Pardatscher F, Erdogmus S, Philipp M, Gregoritza $M$, et al. Dynamic NHERF interaction with TRPC4/5 proteins is required for channel gating by diacylglycerol. Proc Natl Acad Sci USA 2017; 114(1): E37-E46. https://doi.org/10.1073/pnas.1612263114.

13. Wilkes M, Madej MG, Kreuter L, Rhinow D, Heinz V, De Sanctis S, et al. Molecular insights into lipid-assisted $\mathrm{Ca}^{2+}$ regulation of the TRP channel Polycystin-2. Nat Struct Mol Biol 2017; 24(2): 123-130. https://doi.org/10.1038/nsmb.3357.

14. Dietrich A. Modulators of transient receptor potential (TRP) channels as therapeutic options in lung disease. Pharmaceuticals (Basel) 2019; 12(1): 23. https://doi.org/10.3390/ph12010023.

15. Steinritz D, Stenger B, Dietrich A, Gudermann T, Popp T. TRPs in tox: involvement of transient receptor potential-channels in chemicalinduced organ toxicity-a structured review. Cells 2018; 7(8): E98. https://doi.org/10.3390/cells7080098.

16. Marsakova L, Barvik I, Zima V, Zimova L, Vlachova V. The first extracellular linker is important for several aspects of the gating mechanism of human TRPA1 channel. Front Mol Neurosci 2017; 10: 16. https://doi.org/10.3389/fnmol.2017.00016.

17. Yin Y, Wu M, Zubcevic L, Borschel WF, Lander GC, Lee SY. Structure of the cold- and menthol-sensing ion channel TRPM8. Science 2018; 359(6372): 237-241. https://doi.org/10.1126/science.aan4325.
18. Dietrich A, Steinritz D, Gudermann T. Transient receptor potential (TRP) channels as molecular targets in lung toxicology and associated diseases. Cell Calcium 2017; 67: 123-137. https://doi.org/10.1016/j.ceca.2017.04.005.

19. Banner KH, Igney F, Poll C. TRP channels: emerging targets for respiratory disease. Pharmacol Ther 2011; 130(3): 371-384. https://doi.org/10.1016/j.pharmthera.2011.03.005.

20. Singh AK, McGoldrick LL, Sobolevsky Al. Structure and gating mechanism of the transient receptor potential channel TRPV3. Nat Struct Mol Biol 2018; 25(9): 805-813. https://doi.org/10.1038/s41594018-0108-7.

21. Yang J, Yu HM, Zhou XD, Kolosov VP, Perelman JM. Study on TRPV1mediated mechanism for the hypersecretion of mucus in respiratory inflammation. Mol Immunol 2013; 53(1-2): 161-171. https://doi.org/10.1016/i.molimm.2012.06.015.

22. Mabalirajan $U$, Rehman R, Ahmad T, Kumar S, Singh S, Leishangthem GD, et al. Linoleic acid metabolite drives severe asthma by causing airway epithelial injury. Sci Rep 2013; 3: 1349. https://doi.org/10.1038/srep01349.

23. Baxter M, Birrell MA, Belvisi MG. The role of TRPV1 in tobacco smoke induced airway inflammation. Am J Respir Crit Care Med 2012; 185 A6410. conference.2012.185.1_MeetingAbstracts.A6410.

24. McGarvey LP, Butler CA, Stokesberry S, Polley L, McQuaid S, Abdullah $\mathrm{H}$, et al. Increased expression of bronchial epithelial transient receptor potential vanilloid 1 channels in patients with severe asthma. J Allergy Clin Immunol 2014; 133(3): 704-712. https://doi.org/10.1016/i.jaci.2013.09.016.

25. Deng Z, Paknejad N, Maksaev G, Sala-Rabanal M, Nichols CG, Hite RK, et al. Cryo-EM and X-ray structures of TRPV4 reveal insight into ion permeation and gating mechanisms. Nat Struct Mol Biol 2018; 25(3): 252-260. https://doi.org/10.1038/s41594-018-0037-5.

26. Duan J, Li J, Zeng B, Chen GL, Peng X, Zhang $Y$, et al. Structure of the mouse TRPC4 ion channel. Nat Commun 2018; 9(1): 3102. https://doi.org/10.1038/s41467-018-05247-9.

27. Balakrishna S, Song W, Achanta S, Doran SF, Liu B, Kaelberer MM, et al. TRPV4 inhibition counteracts edema and inflammation and improves pulmonary function and oxygen saturation in chemically induced acute lung injury. Am J Physiol Lung Cell Mol Physiol 2014; 307(2): L158-L172. https://doi.org/10.1152/ajplung.00065.2014.

28. Poole DP, Amadesi S, Veldhuis NA, Abogadie FC, Lieu T, Darby W, et al. Protease-activated receptor-2 (PAR2) and transient receptor potential Vanilloid 4 (TRPV4) coupling is required for sustained inflammatory signaling. J Biol Chem 2013; 288(8):5790-802. https://doi.org/10.1074/ibc.M112.438184.

29. Nesin V, Tsiokas L. TRPC1. Handb Exp Pharmacol 2014; 222: 15-51. https://doi.org/10.1007/978-3-642-54215-2 2.

30. Ross GR, Bajwa T Jr, Edwards S, Emelyanova L, Rizvi F, Holmuhamedov $E L$, et al. Enhanced store-operated Ca2+influx and ORAI1 expression in ventricular fibroblasts from human failing heart. Biol Open 2017; 6(3): 326-332. https://doi.org/10.1242/bio.022632.

31. Li N, He Y, Yang G, Yu Q, Li M. Role of TRPC1 channels in pressuremediated activation of airway remodeling. Respir Res 2019; 20(1): 91. https://doi.org/10.1186/s12931-019-1050-x.

32. Hofmann K, Fiedler S, Vierkotten S, Weber J, Klee S, Jia J, et al. Classical transient receptor potential 6 (TRPC6) channels support myofibroblast differentiation and development of experimental pulmonary fibrosis. Biochim Biophys Acta Mol Basis Dis 2017; 1863(2): 560-568. https://doi.org/10.1016/j.bbadis.2016.12.002.

33. Lin AH, Liu MH, Ko HB, Perng DW, Lee TS, Kou YR. Inflammatory effects of menthol vs. non-menthol cigarette smoke extract on human lung epithelial cells: a double-hit on TRPM8 by reactive oxygen species and menthol. Front Physiol 2017; 8: 263. https://doi.org/10.3389/fphys.2017.00263. 
34. Kytikova OY, Novgorodtseva TP, Antonyuk MV, Denisenko YK, Gvozdenko TA. Molecular targets of fatty acid ethanolamides in asthma. Medicina (Kaunas) 2019; 55(4): E87. https://doi.org/10.3390/medicina55040087.

35. Kudaibergenova M, Perissinotti LL, Noskov SY. Lipid roles in herg function and interactions with drugs. Neurosci Lett 700: 70-77. https://doi.org/10.1016/j.neulet.2018.05.019.

36. Hellmich UA, Gaudet R. Structural biology of TRP channels. Handb Exp Pharmacol 2014; 223: 963-990. https://doi.org/10.1007/978-3-31905161-1_10.

37. Zygmunt PM, Högestätt ED. Trpa1. Handb Exp Pharm 2014; 222: 583630. https://doi.org/10.1007/978-3-642-54215-2_23.

38. Hansen SB. Lipid Agonism: The PIP2 paradigm of ligand-gated ion channels. Biochim Biophys Acta 2015; 1851(5): 620-628. https://doi.org/10.1016/j.bbalip.2015.01.011.

39. Poveda JA, Marcela Giudici A, Lourdes Renart M, Morales A, GonzálezRos JM. Towards understanding the molecular basis of ion channel modulation by lipids: Mechanistic models and current paradigms. Biochim Biophys Acta Biomembr 2017; 1859(9 Pt B): 1507-1516. https://doi.org/10.1016/j.bbamem.2017.04.003.

40. Liu H, Liu Q, Hua L, Pan J. Inhibition of transient receptor potential melastatin 8 alleviates airway inflammation and remodeling in a murine model of asthma with cold air stimulus. Acta Biochim Biophys Sin (Shanghai) 2018; 50(5): https://doi.org/10.1093/abbs/gmy033.

41. Long L, Yao H, Tian J, Luo W, Yu X, Yi F, et al. Heterogeneity of cough hypersensitivity mediated by TRPV1 and TRPA1 in patients with chronic refractory cough. Respir Res 2019; 20(1): 112. https://doi.org/10.1186/s12931-019-1077-z.

42. Shapiro D, Deering-Rice CE, Romero EG, Hughen RW, Light AR, Veranth $\mathrm{JM}$, et al. Activation of transient receptor potential ankyrin-1 (TRPA1) in lung cells by wood smoke particulate material. Chem Res Toxicol 2013; 26(5): 750-758. https://doi.org/10.1021/tx400024h.

43. Turcotte C, Chouinard F, Lefebvre JS, Flamand N. Regulation of inflammation by cannabinoids, the endocannabinoids 2-arachidonoylglycerol and arachidonoyl-ethanolamide, and their metabolites. J Leukoc Biol 2015; 97(6): 1049-1070. https://doi.org/10.1189/jlb.3RU0115-021R

44. Le Boisselier R, Alexandre J, Lelong-Boulouard V, Debruyne D. Focus on cannabinoids and synthetic cannabinoids. Clin Pharmacol Ther 2017; 101(2): 220-229. https://doi.org/10.1002/cpt.563.

45. Muller C, Morales $\mathrm{P}$, Reggio $\mathrm{PH}$. Cannabinoid ligands targeting TRP channels. Front Mol Neurosci 2019; 11: 487. https://doi.org/10.3389/fnmol.2018.00487.

46. Petrosino S, Di Marzo V. The pharmacology of palmitoylethanolamide and first data on the therapeutic efficacy of some of its new formulations. $\mathrm{Br} J$ Pharmacol 2017; 174(11): 1349-1365. https://doi.org/10.1111/bph.13580.

47. Ruiz de Azua I, Lutz B. Multiple endocannabinoid-mediated mechanisms in the regulation of energy homeostasis in brain and peripheral tissues. Cell Mol Life Sci 2019; 76(7): 1341-1363. https://doi.org/10.1007/s00018-018-2994-6.

48. Ferrini ME, Hong S, Stierle A, Stierle D, Stella N, Roberts K, et al. CB2 receptors regulate natural killer cells that limit allergic airway inflammation in a murine model of asthma. Allergy 2017; 72(6): 937 947. https://doi.org/10.1111/all.13107.

49. Picazo-Juárez G, Romero-Suárez $S$, Nieto-Posadas $A$, Llorente I, JaraOseguera $A$, Briggs $M$, et al. Identification of a binding motif in the S5 helix that confers cholesterol-sensitivity to TRPV1. J Biol Chem 2011; 286(28): 24966-24976. https://doi.org/10.1074/jbc.M111.237537.

50. Rosenhouse-Dantsker A, Noskov S, Durdagi S, Logothetis DE, Levitan I. Identification of novel cholesterol-binding regions in Kir2 channels. $J$ Biol Chem 2013; 288(43): 31154-31164. https://doi.org/10.1074/jbc.M113.496117.
51. daCosta CJ, Dey L, Therien JP, Baenziger JE. A distinct mechanism for activating uncoupled nicotinic acetylcholine receptors. Nat Chem Biol 2013; 9(11): 701-707. https://doi.org/10.1038/nchembio.1338.

52. Diaz-Rohrer BB, Levental KR, Simons K, Levental I. Membrane raft association is a determinant of plasma membrane localization. Proc Natl Acad Sci USA 2014; 111(23): 8500-8505. https://doi.org/10.1073/pnas.1404582111.

53. Tulodziecka K, Diaz-Rohrer BB, Farley MM, Chan RB, Di Paolo G, Levental KR, et al. Remodeling of the postsynaptic plasma membrane during neural development. Mol Biol Cell 2016; 27(22): 3480-3489. https://doi.org/10.1091/mbc.E16-06-0420.

54. Hou TY, Barhoumi R, Fan YY, Rivera GM, Hannoush RN, McMurray DN, et al. $n-3$ polyunsaturated fatty acids suppress $C D 4(+) \quad T$ cell proliferation by altering phosphatidylinositol-(4,5)-bisphosphate [PI(4,5)P2] organization. Biochim Biophys Acta 2016; 1858(1): 85-96. https://doi.org/10.1016/j.bbamem.2015.10.009.

55. Sciacca MF, Lolicato F, Di Mauro G, Milardi D, D’Urso L, Satriano C, et al. The role of cholesterol in driving iapp-membrane interactions. Biophys J 2016; 111(1): 140-151. https://doi.org/10.1016/j.bpj.2016.05.050.

56. Hellwing C, Tigistu-Sahle F, Fuhrmann H, Käkelä R, Schumann J. Lipid composition of membrane microdomains isolated detergent-free from PUFA supplemented RAW264.7 macrophages. J Cell Physiol 2018; 233(3): 2602-2612. https://doi.org/10.1002/jcp.26138.

57. Carroll RG, Zasłona Z, Galván-Peña S, Koppe EL, Sévin DC, Angiari S, et al. An unexpected link between fatty acid synthase and cholesterol synthesis in proinflammatory macrophage activation. J Biol Chem 2018; 293(15): 5509-5521. https://doi.org/10.1074/ibc.RA118.001921.

58. Varshney $P$, Yadav V, Saini N. Lipid rafts in immune signalling: current progress and future perspective. Immunology 2016; 149(1): 13-24. https://doi.org/10.1111/imm.12617.

59. Grouleff J, Irudayam SJ, Skeby KK, Schiøtt B. The influence of cholesterol on membrane protein structure, function, and dynamics studied by molecular dynamics simulations. Biochim Biophys Acto 2015. 1848(9): 1783-1795. https://doi.org/10.1016/i.bbamem.2015.03.029.

60. Levitan I, Singh DK, Rosenhouse-Dantsker A. Cholesterol binding to ion channels. Front Physiol 2014; 5: 65. https://doi.org/10.3389/fphys.2014.00065

61. Fantini J, Barrantes FJ. How cholesterol interacts with membrane proteins: an exploration of cholesterol-binding sites including CRAC, CARC and tilted domains. Front Physiol 2013; 4: 31. https://doi.org/10.3389/fphys.2013.00031.

62. Saha S, Ghosh A, Tiwari N, Kumar A, Kumar A, Goswami C. Preferential Selection of Arginine at the Lipid-Water-Interface of Trpv1 During Vertebrate Evolution Correlates with Its Snorkeling Behaviour and Cholesterol Interaction. Sci Rep 2017; 7(1): 16808 https://doi.org/10.1038/s41598-017-16780-w.

63. Peng JB. TRPV5 and TRPV6 in transcellular Ca (2+) transport: Regulation, gene duplication, and polymorphisms in African populations. Adv Exp Med Biol 2011; 704: 239-275. https://doi.org/10.1007/978-94-007-0265-3 14.

64. Achanta S, Chintagari NR, Brackmann M, Balakrishna S, Jordt SE. TRPA1 and CGRP antagonists counteract vesicant-induced skin injury and inflammation. Toxicol Lett 2018; 293: 140-148. https://doi.org/10.1016/j.toxlet.2018.03.007.

65. Devos FC, Boonen B, Alpizar YA, Maes T, Hox V, Seys S, et al. Neuroimmune interactions in chemical-induced airway hyperreactivity. Eur Respir J 2016; 48: 380-392. https://doi.org/10.1183/13993003.01778$\underline{2015}$.

66. Alpizar YA, Boonen B, Sanchez A, Jung C, López-Requena A, Naert R, et al. TRPV4 activation triggers protective responses to bacterial lipopolysaccharides in airway epithelial cells. Nat Commun 2017; 8(1): 1059. https://doi.org/10.1038/s41467-017-01201-3. 
67. Taylor-Clark TE. Role of reactive oxygen species and TRP channels in the cough reflex. Cell Calcium 2016; 60(3): 155-162. https://doi.org/10.1016/j.ceca.2016.03.007.

68. Raemdonck K, de Alba J, Birrell MA, Grace M, Maher SA, Irvin CG, et al. A role for sensory nerves in the late asthmatic response. Thorax 2012; 67(1): 19-25. https://doi.org/10.1136/thoraxjnl-2011-200365

69. Hox V, Vanoirbeek JA, Alpizar YA, Voedisch S, Callebaut I, Bobic S, et al. Crucial role of transient receptor potential ankyrin 1 and mast cells in induction of nonallergic airway hyperreactivity in mice. Am J Respir Crit Care Med 2013; 187(5): 486-493. https://doi.org/10.1164/rccm.201208-13580C.

70. Gimpl G. Interaction of G Protein Coupled Receptors and Cholesterol. Chem Phys Lipids 2016; 199: 61-73. https://doi.org/10.1016/j.chemphyslip.2016.04.006.

71. Gao Y, Cao E, Julius D, Cheng Y. TRPV1 structures in nanodiscs reveal mechanisms of ligand and lipid action. Nature 2016; 534 (7607): 347351. https://doi.org/10.1038/nature17964.

72. Takahashi N, Hamada-Nakahara S, Itoh Y, Takemura K, Shimada A, Ueda $Y$, et al. TRPV4 channel activity is modulated by direct interaction of the ankyrin domain to $\mathrm{Pl}(4,5) \mathrm{P}(2)$. Nat Commun 2014; 5: 4994. https://doi.org/10.1038/ncomms5994.

73. Li MC, Yang G, Zhou XD, Tselluyko S, Perelman JM. The pathophysiological mechanisms underlying mucus hypersecretion induced by cold temperatures in cigarette smoke-exposed rats. Int J Mol Med 2014; 33(1): 83-90. https://doi.org/10.3892/ijmm.2013.1535.

74. Grace M, Birrell MA, Dubuis E, Maher SA, Belvisi MG. Transient receptor potential channels mediate the tussive response to prostaglandin E2 and bradykinin. Thorax 2012; 67(10): 891-900. https://doi.org/10.1136/thoraxjnl-2011-201443.

\section{Authors:}

Oxana Yu. Kytikova - MD, DSc, Researcher, Laboratory of Rehabilitative Treatment, Vladivostok Branch of Far Eastern Scientific Center of Physiology and Pathology of Respiration - Institute of Medical Climatology and Rehabilitative Treatment, Vladivostok, Russia. http://orcid.org/00000001-5018-0271

Tatyana P. Novgorodtseva - MD, DSc, Professor, Chief Researcher, Laboratory of Biomedical Research, Vladivostok Branch of Far Eastern Scientific Center of Physiology and Pathology of Respiration - Institute of Medical Climatology and Rehabilitative Treatment, Vladivostok, Russia. http://orcid.org/0000-0002-6058-201x.

Yulia K. Denisenko - MD, DSc, Head of the Laboratory of Biomedical reSearch, Vladivostok Branch of Far Eastern Scientific Center of Physiology and Pathology of Respiration - Institute of Medical Climatology and Rehabilitative Treatment, Vladivostok, Russia. http://orcid.org/0000-00034130-8899.

Marina V. Antonyuk - MD, DSc, Professor, Head of the Laboratory of Rehabilitation Treatment, Vladivostok Branch of Far Eastern Scientific Center of Physiology and Pathology of Respiration - Institute of Medical Climatology and Rehabilitative Treatment, Vladivostok, Russia. https://orcid.org/0000-0002-2492-3198.

Tatyana A. Gvozdenko - MD, DSc, Professor of Russian Academy of Sciences, Chief Researcher, Laboratory of Rehabilitation Treatment, Vladivostok Branch of Far Eastern Scientific Center of Physiology and Pathology of Respiration - Institute of Medical Climatology and Rehabilitative Treatment, Vladivostok, Russia. http://orcid.org/0000-00026413-9840. 